\title{
Avaliação muscular isocinética da musculatura abdutora e adutora de coxa em atletas de natação do estilo peito
}

\author{
Flávia R. Ihara ${ }^{1}$, Mirco Cevales ${ }^{2}$ e Sergio de Souza Pinto ${ }^{3}$
}

\section{RESUMO}

Foi realizada nesta pesquisa a avaliação isocinética de 12 atletas da natação do estilo peito, com idades entre 15 e 22 anos, submetidos a treinamento diário, encontrando-se em performance estadual e nacional. Todos foram avaliados pelo aparelho de avaliação muscular isocinético computadorizado da marca Cybex, no seu modelo Norm, na Clínica de Fisioterapia da Unicid. Foi avaliada a musculatura adutora e abdutora de quadril. Foram utilizados os dados obtidos a 30 graus por segundo em cinco repetições. Os resultados transformados em percentagem para uma melhor comparação entre outros trabalhos, pois já está considerando o peso do paciente. Obtiveram-se a média, a máxima e a mínima do torque desenvolvido por esta musculatura, sendo observada a relação com a amplitude do movimento e a simetria entre os dois membros. Os resultados mostraram um torque dominante em adutores, uma assimetria entre os dois membros. Observou-se um torque médio em adutor de $150,05 \%$ e abdutor em $127,06 \%$.

Palavras-chave: Natação. Isocinético. Abdutor. Adutor.

1. Fisioterapeuta.

2. Professor de Educação Física; Técnico de Natação; Ex-Técnico da Seleção Brasileira Juvenil e de Júnior de Natação; Técnico da Equipe de Natação de São Caetano do Sul.

3. Fisioterapeuta; Especialista em Traumatologia Desportiva; Mestrando em Educação; Prof. de Fisioterapia Ortopédica e Traumatológica (Unicid); Supervisor de Ortopedia (Unicid); Coordenador da Pós-Graduação em Ortopedia (Unicid); Responsável pela Avaliação Isocinetica na Unicid.

Endereço para correspondência:

Sergio de Souza Pinto

Rua Marquês de Três Rios, 242, ap. 45, Bl. 1 - Botafogo

13020-030 - Campinas, SP

Tel. (0xx19) 233-3941

E-mail: sergiocris@uol.com.br

Rev Bras Med Esporte - Vol. 6, № 3 - Mai/Jun, 2000

\section{ABSTRACT}

Isokinetic evaluation of the abductor and adductor musculature of the thigh in swimming athletes performing chest swimming style

In this study, an isokinetic evaluation of 12 swimming athletes performing the chest swimming style, ages ranging from 15 to 22 years, submitted to daily training and participating in state and national performances was conducted. A Cybex isokinetic computerized device model Norm was used to evaluate all athletes at the Unicid physical therapy clinic. The muscular abduction and adduction of the hip were evaluated. Data obtained from a series of five repetitions at 30 degrees were used. Since the patient's weight had already been considered, results were converted into percentage numbers to provide for a better comparison with other studies on the same subject. The authors obtained the average, maximum, and minimum torque performed by the musculature, considering its relation to the extension of the movement and the symmetry between the two members. An average torque of $150.05 \%$ for adduction and $127.06 \%$ for abduction was found.

Key words: Swimming. Isokinetic. Abductor. Adductor.

\section{INTRODUÇÃO}

A natação é um esporte conhecido desde a Grécia e Roma, onde soldados o praticavam como parte de seu treinamento. Porém, somente no início do século XX começou a se desenvolver como desporto, vindo a ser estudada mais aprofundadamente nos últimos $20 \operatorname{anos}^{1,2}$.

Segundo Gomes ${ }^{1}$, natação é toda prática humana na água ou na sua superfície, que exclui o uso de qualquer artifício para atingir total autonomia no meio.

Atualmente, existem cinco estilos competitivos praticados na natação: o $\mathrm{crawl}$, borboleta, costas, peito e o nado medley. Este último consiste no somatório dos outros quatro estilos, e cada vez mais vem crescendo o número de competidores nesta modalidade ${ }^{3,4}$.

O estilo crawl é o mais rápido dos estilos de competição. A posição do nadador consiste em uma pronação, com a cabeça baixa na linha da água, com os quadris ligeira- 
mente mais baixos que os ombros, e as pernas estendidas para trás. No estilo borboleta, a única diferença é que os braços e as pernas se movem juntos num movimento ondulatório. O nado de costas também é conhecido como crawl invertido. Neste nado, o nadador fica na posição supina, com tronco e pernas ligeiramente estendidos e os quadris abaixo do nível da água. O nado de peito foi o primeiro estilo de natação a ser desenvolvido e vai ser melhor descrito posteriormente. Finalmente, o quinto estilo competitivo, que é o medley, consiste respectivamente no somatório dos estilos borboleta, costas, peito e $\mathrm{crawl}^{3,4}$.

Durante uma competição, o principal objetivo de um nadador é nadar a distância total de sua prova seguindo as regras oficiais que regulamentam a saída, execução do nado, virada, chegada, no menor tempo possível, e obter a máxima velocidade da qual é capaz ${ }^{4}$.

O desempenho do atleta de natação depende de vários elementos, tais como: o equilíbrio, a resistência, coordenação, força, propulsão e a respiração. Além desses elementos, há ainda o empuxo e o peso, que em conjunto determinarão a imersão e a flutuabilidade do nadador ${ }^{2}$.

A prática da natação exige uma série de movimentos repetitivos; com isso é gerado um aumento do rendimento da contração muscular, que conseqüentemente leva ao aumento do tônus, que corresponde ao estado de tensão em que o músculo se encontra em repouso ${ }^{5}$.

$\mathrm{O}$ nado de peito foi o primeiro nado a ser desenvolvido. Neste nado, o atleta mais completo é o atleta mais bem sucedido. Como o meio aquático não pode proporcionar a resistência necessária para aumentar devidamente a carga no sistema muscular, o nadador volta-se para a sala de musculação. Uma parte integrante do programa de treinamento da natação consiste no treinamento de força e resistência em seco. Este nado é o único nado em que os membros superiores e inferiores produzem a maior parte da propulsão. O nado envolve uma movimentação articular complexa em diversas áreas da anatomia. A ação do braço no nado de peito pode ser dividida em quatro fases distintas: tomada, varredura para baixo, varredura para dentro e recuperação ${ }^{6}$.

Nesta fase o nadador inicia a fase de puxada da braçada com os braços estendidos para a frente, paralelos à superfície da água. As mãos são voltadas para cima, de modo que as palmas estejam a quase 90 graus para fora a partir da posição pronada. Ocorre uma ligeira torção do punho, fazendo com que a mão do nadador tome a forma côncava. Nesta posição o atleta está preparado para dar início à fase propulsora da braçada. No final da tomada, os braços encontram-se ligeiramente mais abertos que a largura dos ombros. Músculos como tríceps braquial, redondo maior, flexores de punho superficiais e profundos, peitoral, grande dorsal, braquiorradial, braquial e bíceps braquial vão estar agindo nesta fase ${ }^{6}$.

$\mathrm{Na}$ fase de varredura para baixo o braço começa a curvar-se no cotovelo à medida que as mãos descrevem um movimento circular para baixo e para fora. As palmas encontram-se voltadas lateralmente, embora já tenham iniciado o giro internamente. Ao final deste movimento as mãos estarão em seu ponto mais profundo da braçada, com flexão de cotovelo de quase 90 graus. Durante este movimento o nadador começa a levantar a cabeça para tomar fôlego. Ao final da varredura para baixo as mãos começam a se acelerar, e esta aceleração é mantida até a fase de varredura para dentro. Músculos como bíceps braquial, braquial, braquiorradial, subescapular, redondo maior, peitoral maior, grande dorsal, dorsal longo do pescoço, semiespinhal do pescoço, esplênio da cabeça, esplênio do pescoço e eretores da coluna vão estar atuando nesta fase. $\mathrm{Na}$ fase de varredura para dentro o movimento das mãos muda do sentido para baixo e para fora, para o sentido interno e para cima, continuando o padrão circular iniciado com a varredura para baixo.

As mãos correm quase diretamente para baixo dos cotovelos, quando se aproximam da linha central do corpo. Quando as mãos se juntam abaixo do queixo, os cotovelos são trazidos juntos por baixo do tórax. Quando o cotovelo se aproxima um do outro, o nadador respira. Músculos como bíceps braquial, braquiorradial, braquial, supinador, peitoral maior, grande dorsal, redondo maior e trapézio vão estar atuando nesta fase ${ }^{6}$.

$\mathrm{Na}$ fase de recuperação, quando as mãos se encontram sob o queixo e os cotovelos são aproximados, os braços se estendem para a frente, paralelos à superfície da água. A cabeça volta para dentro da água. Quando os braços atingem a extensão completa, as mãos são empurradas 15 a $20 \mathrm{~cm}$ para baixo. Isto é para evitar que o quadril caia abaixo da superfície, mantendo assim o posicionamento adequado do corpo. Músculos como tríceps braquial, deltóide, peitoral maior, coracobraquial atuam nesta fase. A pernada do nado de peito também se divide em quatro fases: tomada, varredura para baixo, varredura para dentro e recuperação ${ }^{6}$.

Na fase de tomada os joelhos estão completamente fletidos (mais de 90 graus). Os pés encontram-se acima das nádegas, juntos. O movimento dos pés é girado de modo que as solas fiquem voltadas para trás e para cima, com os dedos apontando lateralmente. As pernas começam a se estender e os pés fazem o percurso no sentido para trás e para fora, nas laterais. Músculos como tibial anterior, dorsiflexores, glúteo médio, tensor da fascia lata, iliopsoas, quadríceps atuam nesta fase ${ }^{6}$. 
$\mathrm{Na}$ fase de varredura para baixo as pernas continuam a extensão iniciada na fase anterior. Esta extensão faz com que os pés percorram em sentido para baixo e para fora até atingirem o ponto mais aberto, quando iniciam o percurso de volta para dentro e para baixo. O movimento dos pés muda em sentido interno. Músculos como adutor magno, adutor curto, adutor longo, pectíneo e grácil atuam nesta fase. Funcionam como propulsores do nado ${ }^{6}$.

$\mathrm{Na}$ fase de varredura para dentro os pés continuam a girar para dentro. As pernas terminam a extensão e então os pés são trazidos para perto um do outro. Quando os pés estão quase se tocando, pode ocorrer um breve deslize, pois as pernas mantêm esse posicionamento de extensão completa por uma fração de segundos. Músculos como quadríceps, tibial anterior, tibial posterior, gastrocnêmio, sóleo, atuam nesta fase ${ }^{6}$.

$\mathrm{Na}$ fase de recuperação, no final da parte propulsora da pernada, os pés se encontram juntos. Nesta posição eles estão prontos para iniciar a recuperação. As pernas recuperam quando os braços geram a propulsão. Músculos como o bíceps femoral, semitendinoso, semimembranoso, sartório e grácil atuam nesta fase ${ }^{6}$.

Como foi visto, o nado de peito é muito complexo. Para uma boa pernada neste nado é necessário ter músculos adutores de coxa fortes, para que a propulsão do nado seja eficiente. Só que não é só da força que depende o desempenho de um nadador; precisa-se também da eficiência mecânica, flexibilidade, continuidade e bom posicionamento (Lima 1996).

A amplitude de movimento também é muito importante. Quanto mais alongado o músculo, maior sua capacidade de gerar força. O comprimento do músculo aumenta com o treinamento do alongamento. Quando se faz alongamento, o músculo resiste, mas aumenta-se o comprimento do sarcômero (afasta os filamentos finos dos grossos). Alongando a fibra, o comprimento de repouso muda, aumentando. A fibra vai estar relaxada, mas o comprimento de repouso vai ser maior?

Em qualquer atividade física que ocorre em tempo superior a alguns minutos, a energia é fornecida pelo sistema aeróbico. Os exercícios de resistência provocam adaptações musculares que controlam o fornecimento de energia. As adaptações que ocorrem com o treinamento promovem alterações no metabolismo muscular, adaptando-os para aumentar as trocas entre os capilares e as células, e, conseqüentemente, uma melhoria no desempenho físico. O músculo quando adaptado ao treinamento utiliza melhor a reserva de energia. Só que os músculos que não são requisitados no programa de treinamento não se adaptam; é por isso que cada vez mais se faz necessário o conhecimento de biomecânica do movimento de acordo com o estilo do atleta. Um programa de alongamento adequado pode melhorar o desempenho de um atleta, tendo em vista que qualquer um dos cinco estilos vai exigir uma grande amplitude de movimento das articulações e, se a musculatura alcançar o comprimento ideal, irá ajudar o atleta no desenvolvimento de potência e resistência muscular ${ }^{8}$.

Atualmente, a natação é um esporte que vem crescendo muito nacional e internacionalmente, graças ao bom desempenho que os nadadores(as) vêm apresentando nas competições. Entretanto, a maior e mais preocupante deficiência competitiva da natação está no estilo peito, que necessita de uma pernada forte e de uma boa flexibilidade no arco de movimento. Embora apresente bons nadadores neste estilo, a maioria utiliza a coordenação de movimento e a força de braços para sustentar o nado, não fazendo uso de uma forte e eficiente pernada, sendo necessária uma avaliação da força muscular de adutores/abdutores de coxa em nadadores de peito?.

A coxa é constituída de três compartimentos musculares: anterior, posterior e medial. No compartimento anterior da coxa encontra-se o músculo quadríceps femoral (músculo vasto lateral, músculo vasto medial, músculo vasto intermédio, músculo reto femoral) e o músculo sartório (oblíquo). No compartimento medial da coxa encontramse os músculos que vão fazer a adução da coxa, tal como o músculo adutor magno, músculo adutor longo, músculo adutor curto, músculo pectíneo e músculo grácil. No compartimento posterior da coxa encontram-se os músculos bíceps femoral, músculo semitendinoso e músculo semimembranoso ${ }^{10}$.

Entre os movimentos realizados pela coxa observam-se: abdução, adução, flexão, extensão, rotação externa e rotação interna ${ }^{11}$.

Considerando-se os músculos como um sistema biológico que transforma energia química em mecânica, a avaliação de sua função envolve a determinação das variáveis: força, trabalho, potência e resistência ${ }^{12}$.

A força pode ser definida simplesmente como um empurrão ou tração. Uma equação usada para definir a força é $F=m \times a$, onde $F$ é a força, $m$ é a massa do objeto e $a$ é a aceleração do objeto. Por definição, força é uma entidade que tende a produzir movimento. A força produzida por um músculo depende de vários fatores ${ }^{13}$.

Fazem parte desses fatores: a) sincronização das unidades motoras; b) seção transversa do músculo, que deriva da massa e diâmetro das fibras musculares; c) tipo de fibra muscular predominante; d) disposição anatômica das fibras musculares; e) sistemas de alavancas articulares; f) fatores etários e endócrinos ${ }^{12}$.

Quando se mensuram as forças exercidas sobre os sistemas articulares através da isocinética, leva-se em conside- 
ração o momento ou torque desenvolvido pelos grupos musculares. Torque ou momento é quando uma força atua sobre um corpo e tende a produzir um movimento angular. $\mathrm{O}$ movimento angular sempre ocorre ao redor do centro de rotação, chamado de eixo. O torque de uma força sobre um eixo é o produto da força e do seu braço de alavanca ${ }^{14,15}$.

Isocinética significa constância das forças em movimento. Durante o treinamento isocinético, a velocidade com que a carga é movimentada é mantida constante. Isto naturalmente significa também uma velocidade constante da contração muscular. Trata-se, portanto, de uma forma de treinamento de força dinâmica. Maquinalmente, a velocidade permanece constante e a carga fica adaptada ao ângulo de ataque e a distensão prévia da fibra muscular. Mediante o treinamento isocinético, poderá ser mobilizada uma força constante no total da trajetória dos movimentos ${ }^{16}$.

Um dinamômetro isocinético é um instrumento eletromecânico contendo um mecanismo controlador de velocidade e que acelera até uma velocidade preestabelecida ao ser aplicada qualquer força. Depois que essa velocidade constante é alcançada, o mecanismo de carga isocinético se acomoda automaticamente para proporcionar uma força contrária e igual à força gerada pelo músculo. Assim sendo, uma força máxima (ou qualquer percentual de esforço máximo) pode ser aplicada durante todas as fases do movimento numa velocidade constante ${ }^{17}$.

O exercício isocinético não estimula os movimentos naturais; assim sendo, é difícil avaliar o treinamento isocinético. O aparelho destinado aos testes isocinéticos é muito útil para testar a força dinâmica máxima. A velocidade de contração é decisiva para a força máxima ${ }^{18}$.

Durante o exercício isocinético a pressão permanece constante durante todo o movimento. O dinamômetro isocinético regula a quantidade de resistência, a sua rapidez e melhora a força muscular, tornando-se indispensável nos esportes de competição ${ }^{19}$.

O exercício isocinético é o único método que pode quantificar a força muscular com precisão, através de equipamentos (dinamômetros isocinéticos) ajustáveis a qualquer tipo de paciente. $\mathrm{O}$ método pode detectar e ajudar na correção de desequilíbrios musculares antes que os sintomas apareçam. No caso dos atletas competitivos isso é essencial, pois pode-se detectar a deficiência do nado caso ela seja de origem muscular ${ }^{20}$.

Portanto, esta pesquisa qualitativo-descritiva propõe uma avaliação isocinética de abdutores e adutores de coxa em nadadores de peito, a fim de avaliar a força muscular e verificar déficits de força nestas musculaturas. Esta pesquisa tem por objetivo comparar dados obtidos no dinamômetro isocinético e fazer uma relação com o grau de amplitude de movimento e a assimetria entre os membros inferiores.

\section{MÉTODO}

Foi construído e aplicado um questionário em 12 nadadores entre 15 e 22 anos, no intuito de avaliar os participantes da pesquisa. Foram colhidos dados sobre idade, peso, atividades extras e informações de treino por eles realizados. Cada atleta teve mensurada sua goniometria de quadril (flexão, extensão, abdução, adução, rotação interna, rotação externa) pelo goniômetro manual. Além do questionário e da goniometria, cada atleta realizou um teste de força muscular de abdutores e adutores de coxa no dinamômetro isocinético, da marca Cybex, modelo Norm, na Clínica de Fisioterapia da Universidade Cidade de São Paulo. O teste foi precedido de um aquecimento na bicicleta ergométrica (15 minutos) e alongamento. O teste inicia-se com o atleta deitado em decúbito lateral na cadeira do dinamômetro, devidamente estabilizado, com a coluna reta e extensão de pernas. $\mathrm{O}$ eixo do dinamômetro é alinhado ao nível de glúteos. A perna que está em cima é que vai ser analisada. O protocolo usado foi uma série de cinco repetições a 30 graus por segundo, em que o resultado em $\mathrm{N} / \mathrm{m}$ foi transformado em percentagem através da divisão do resultado em N/m pelo peso corporal do atleta, multiplicado por 100 , posteriormente. O terapeuta descreve as etapas do teste e da execução correta do movimento. Após análise de uma perna, o atleta muda o decúbito lateral para o outro lado e avalia-se a outra perna. É realizada uma série de cinco repetições de movimento com força máxima do grupo muscular escolhido (abdutores e adutores de coxa).

\section{RESULTADOS E DISCUSSÕES}

O questionário foi aplicado em 12 atletas do sexo masculino. Destes, $75 \%$ pertencem à faixa etária de 15 a 18 anos e $25 \%$ de 19 a 22 anos. Dos atletas avaliados, 83,3\% se encontram em nível de performance nacional e 16,8\% estadual. Quanto ao período de treinamento, 58,3\% treinam mais que três horas por dia, $25 \%$ treinam até três horas e $16,8 \%$ treinam menos que três horas. Todos os atletas praticam somente natação como esporte e apresentam em média $70,2 \mathrm{~kg}$ e $1,76 \mathrm{~m}$ de altura.

Conforme demonstrado na tabela 1 , os atletas realizam preparo físico antes e depois do treino. Antes do treino a

TABELA 1

Tipo de preparo físico

\begin{tabular}{lcc}
\hline Preparo físico & Antes do treino & Depois do treino \\
Musculação & $50 \%$ & - \\
Extensor & $83,3 \%$ & $16,8 \%$ \\
Alongamento & $25 \%$ & $16,8 \%$ \\
Nenhum & - & $66,6 \%$ \\
\hline
\end{tabular}

Rev Bras Med Esporte - Vol. 6, № 3 - Mai/Jun, 2000 


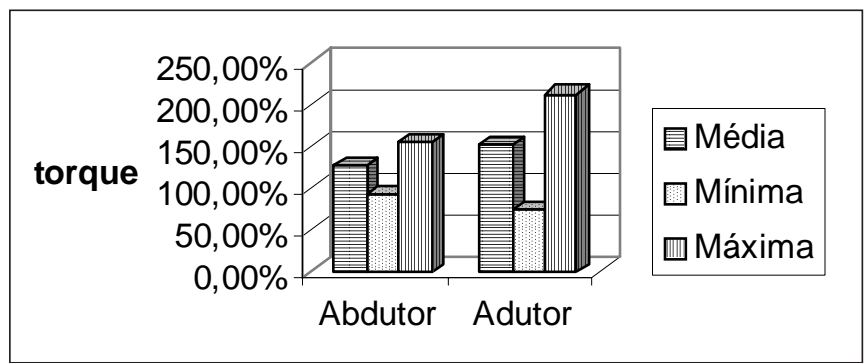

Gráfico 1 - Média, mínima e máximo de torque de abdutor e adutor

maioria dos atletas trabalha mais força de membros superiores com o extensor e metade também complementa o preparo com musculação (exercícios de ombro, braço e de pernas). $\mathrm{O}$ alongamento é muito pouco praticado pelos atletas antes do treino. Depois do treino a maioria dos atletas não realiza nenhuma atividade física. Os atletas que fazem algum preparo físico escolhem entre o extensor e alongamento após o treino. Segundo Nascimento ${ }^{8}$, o alongamento adequado pode melhorar o desempenho do atleta, tanto em potência como em resistência muscular. Daí sua importância dentro do trabalho de preparo físico.

De acordo com dados obtidos no questionário, a maioria dos atletas considera ter uma boa e eficiente pernada no seu nado, alguns relatam que a consideram média e poucos a acham fraca ou ruim.

Foi verificado com o aparelho de avaliação isocinético o torque médio, o máximo e o mínimo dos músculos abdutores e adutores de coxa em nadadores de peito, o que pode ser observado no gráfico 1, e o equilíbrio da relação agonista/antagonista de abdutores e adutores de coxa, que pode ser observado na tabela 2 .

TABELA 2

Déficit de força em adutores e abdutores (\%)

\begin{tabular}{ccc} 
Indivíduos & Abdutores & Adutores \\
1 & 20 & 17 \\
2 & 3 & 8 \\
3 & 14 & 10 \\
4 & 13 & 29 \\
5 & 12 & 11 \\
6 & 17 & 7 \\
7 & 5 & 4 \\
8 & 2 & 11 \\
9 & 8 & 11 \\
10 & 12 & 19 \\
11 & 10 & 17 \\
12 & 18 & 16 \\
Média & 11,2 & 12,4 \\
Máxima & 20 & 29 \\
Mínima & 2 & 4 \\
\hline
\end{tabular}

Rev Bras Med Esporte - Vol. 6, № 3 - Mai/Jun, 2000

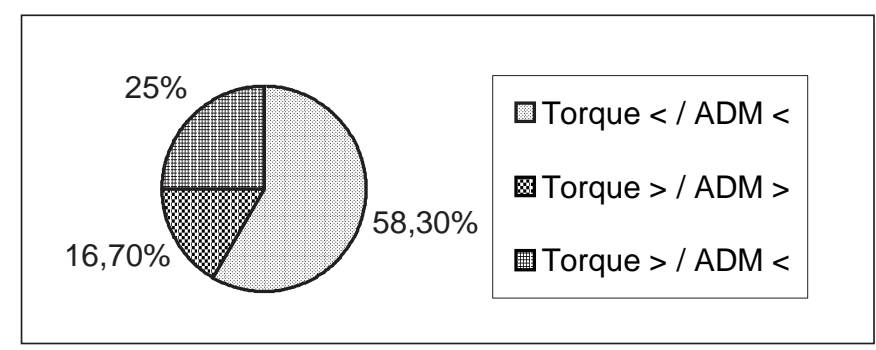

Gráfico 2 - Relação do torque médio com a amplitude de movimento

O gráfico 1 apresenta a média, mínima e máxima do torque de abdutores e adutores de coxa direita e esquerda, onde observamos que a média de torque abdutor foi de $127,6 \%$, chegando no máximo de $154 \%$. Já o adutor atingiu uma média de $150,05 \%$, chegando no máximo a $212 \%$. Para termos uma noção destas características podemos comparar com atletas do futebol, que apresentam um torque máximo de abdutor de $253,40 \%$, com uma média de $166,55 \%$; já o adutor apresentou um máximo de $283,30 \%$, com uma média de $167,60 \%$. Observa-se neste caso uma relação quase igual entre os dois grupos ${ }^{21}$. O que não acontece no caso dos nadadores, que apresentam uma diferença a favor do adutor, sendo ele mais forte que o abdutor. Trabalho realizado por Dvir ${ }^{22}$ mostra que pessoas comuns apresentam um torque de adutor em $172 \%$; já nos abdutores, em $146,6 \%$; isso em população americana.

Na tabela 2 observam-se os déficits de força muscular dos abdutores e dos adutores de coxa, sendo considerado aceitáveis déficits de até $10 \%{ }^{23}$.

$\mathrm{O}$ resultado obtido mostra que todos os atletas apresentam déficit na musculatura adutora, sendo oito atletas $(66,7 \%)$ com déficits considerados acima do aceitável e quatro atletas $(33,3 \%)$ com déficit aceitável.

A musculatura abdutora também apresenta déficits de força, tendo oito atletas $(66,7 \%)$ com déficit acima do aceitável e quatro atletas $(33,3 \%)$ com déficit considerado aceitável.

Foi analisada individualmente a goniometria de quadril (flexão, extensão, abdução, adução, rotação externa e rotação interna) através do goniômetro manual.

Comparando os dados da goniometria e a média de torque obtida (gráfico 2), observa-se que sete atletas $(58,32 \%$ ) apresentam torque menor de adutores de coxa do lado esquerdo, e menor grau de amplitude de movimento deste mesmo lado. Outros dois atletas $(16,7 \%)$ apresentam maior torque de adutores de coxa do lado esquerdo e maior grau de amplitude de movimento deste lado. E três atletas (25\%) apresentam maior torque de adutores de coxa do lado esquerdo, porém menor amplitude de movimento deste lado.

Dos sete atletas que apresentaram torque menor e amplitude de movimento menor do lado esquerdo, apenas três 
(50\%) realizam alongamento antes do treino. Os dois atletas com torque maior de adutores e amplitude de movimento maior do lado esquerdo realizam alongamento antes do treino e um deles também após o treino. E dos três atletas com torque maior e amplitude de movimento menor do lado esquerdo, apenas um realiza alongamento antes do treino.

\section{CONCLUSÃO}

Esta pesquisa qualitativo-descritiva propôs uma avaliação isocinética da força muscular de abdutores e adutores de coxa em nadadores de peito e sua relação com o grau de amplitude do movimento, visando comparar dados de torque da musculatura adutora e abdutora de coxa com o grau de amplitude de movimento dos atletas, verificar déficits de força muscular. Esses dados foram obtidos através do teste isocinético realizado no dinamômetro isocinético da marca Cybex, modelo Norm na Clínica de Fisioterapia da Universidade Cidade de São Paulo, e através do goniômetro manual.

\section{REFERÊNCIAS}

1. Gomes WDF. Natação. Rio de Janeiro: Sprint, 1997.

2. Catteau R, Garoff G. O ensino da natação. $3^{\text {a }}$ ed. São Paulo: Manole, 1988

3. Coulsilman JE. Análise das técnicas desportivas. $2^{\mathrm{a}}$ ed. Rio de Janeiro: Ibero-americana, 1988.

4. Maglischo EW. Nadar ainda mais rápido. Barcelona: Hispano Européia, 1999

5. Guyton AC. Fisiologia do esporte. Em: Tratado de fisiologia médica. $8^{\text {a }}$ ed. Rio de Janeiro: Guanabara Koogan, 1991.

6. Rodeo S. O nado de peito. Sprint magazine. Rio de Janeiro, 1989, n. 2 , p. 6-13, março/abril.

7. Kapandji IA. Membros inferiores. Em: Fisiologia humana. $5^{a}$ ed. São Paulo: Manole, 1990.

8. Nascimento FAG. Lesões nos quatro estilos da natação. Aquática Paulista, São Paulo, 16 de janeiro de 1999, n. 75. Ano V.

9. Cruchinho C. O nado de peito. Trabalho apresentado no $4^{\circ}$ Encontro Ibero-Brasileiro. São José dos Campos, ago. 1997.

10. Hall S. Biomecânica básica. $3^{\mathrm{a}}$ ed. Rio de Janeiro: Guanabara Koogan, 1993.

11. Clarkson HM, Gilewich GB. Avaliação músculo-esquelética. $3^{\mathrm{a}}$ ed. São Paulo: Manole, 1991.
Os resultados das comparações entre torque e grau de amplitude de movimento obtidos nesta pesquisa mostram que graus menores de amplitude de movimento levam a torques menores de força muscular, e que graus menores também podem levar o atleta a não ter alterações no torque de força muscular. Mas isso ocorreu apenas em poucos atletas. Já graus de amplitude maiores levam a torques maiores de força muscular. Esse resultado é compatível com a literatura. E mostra que quanto mais alongado um músculo, maior a amplitude de movimento e, portanto, maior sua capacidade de gerar força, sendo o inverso da mesma forma. Uma hipótese para atletas que tiveram graus menores de amplitude de movimento, mas torques maiores de força muscular, é que a musculatura se adaptou a este grau de amplitude e desenvolveram potência, resistência muscular e força em cima desta estrutura.

Foi observado que, apesar de ser a natação um esporte simétrico, onde os membros têm que estar equilibrados, a média de diferença entre eles foi acima dos $10 \%$ previstos em literatura. E a relação agônico/antagônico está a favor dos adutores, onde eles são mais fortes que os abdutores.

12. Shinzato GT, Batistella LR. Exercício isocinético - Sua utilização para avaliação e reabilitação músculo-esquelética. Âmbito Medicina Desportiva, 1996, 1: 11-8.

13. Gould III JA. Fisioterapia em ortopedia e medicina do esporte, SP, Manole, 1993.

14. Settineri LIC. Biomecânica, noções gerais, RJ, Atheneu, 1998.

15. Hislop HJ, Perrine JJ. The isokinetic concept of exercise, Physical Therapy, New York, 1967, 47: 114-7.

16. Hollmann W. Medicina de esporte, São Paulo, Manole, 1990.

17. McArdle WD. Fisiologia do exercício, RJ, Guanabara Koogan, 1985.

18. Astrand PO. Biblioteca de educação física, $2^{\text {a }}$ ed., SP., Interamericana, 1980.

19. Kupriam W. Fisioterapia nos esportes, SP, Manole, 1984.

20. Lúcio AO. Estudo isocinético. Âmbito Medicina Desportiva 1997, n. 32: 6-7.

21. Miranda IFS. Avaliação muscular isocinética da musculatura adutora e abdutora em jogadores de futebol profissional, Monografia (trabalho de conclusão de curso), Curso de Fisioterapia, Universidade Cidade de São Paulo, SP, 1999.

22. Dvir Z. Isokinetics: muscle testing, interpretation and clinical applications, USA, Churchill Livingstone, 1995.

23. Perrin DH. Isokinetic exercise and assessment, USA, Human Kinetics Publishers, 1993. 